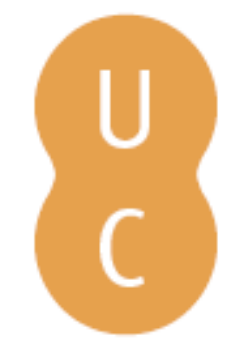

\title{
Rompalina
}

\section{Mapeamento geomorfológico da área urbana de llhéus, Bahia}

\begin{tabular}{ll} 
Autor(es): & $\begin{array}{l}\text { Póvoas, Hogana Sibilla Soares; Fontes, Ednice de Oliveira; Moreau, Ana } \\
\text { Maria dos Santos }\end{array}$ \\
Publicado por: & $\begin{array}{l}\text { Imprensa da Universidade de Coimbra; RISCOS - Associação } \\
\text { Portuguesa de Riscos, Prevenção e Segurança }\end{array}$ \\
$\begin{array}{ll}\text { URL } \\
\text { persistente: }\end{array}$ & URI:http://hdl.handle.net/10316.2/34837 \\
DOI: & DOI:http://dx.doi.org/10.14195/978-989-96253-3-4_41 \\
Accessed : & 26-Apr-2023 14:31:47 \\
\hline
\end{tabular}

A navegação consulta e descarregamento dos títulos inseridos nas Bibliotecas Digitais UC Digitalis, UC Pombalina e UC Impactum, pressupõem a aceitação plena e sem reservas dos Termos e Condições de Uso destas Bibliotecas Digitais, disponíveis em https://digitalis.uc.pt/pt-pt/termos.

Conforme exposto nos referidos Termos e Condições de Uso, o descarregamento de títulos de acesso restrito requer uma licença válida de autorização devendo o utilizador aceder ao(s) documento(s) a partir de um endereço de IP da instituição detentora da supramencionada licença.

Ao utilizador é apenas permitido o descarregamento para uso pessoal, pelo que o emprego do(s) título(s) descarregado(s) para outro fim, designadamente comercial, carece de autorização do respetivo autor ou editor da obra.

Na medida em que todas as obras da UC Digitalis se encontram protegidas pelo Código do Direito de Autor e Direitos Conexos e demais legislação aplicável, toda a cópia, parcial ou total, deste documento, nos casos em que é legalmente admitida, deverá conter ou fazer-se acompanhar por este aviso.

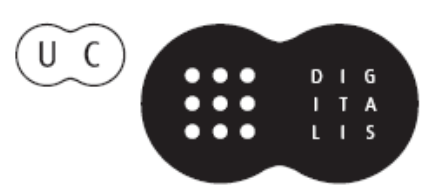



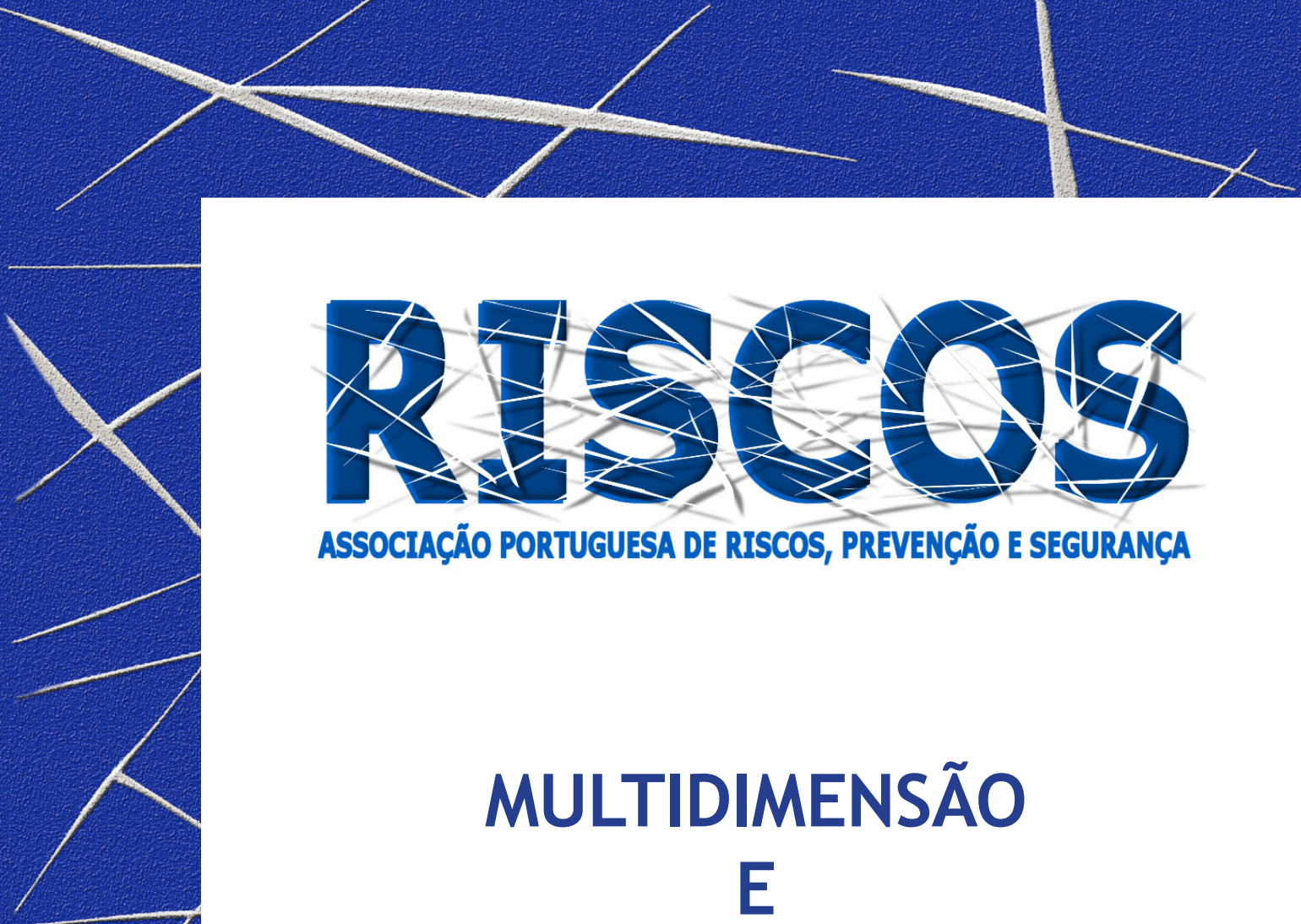

ASSOCIAÇÃO PORTUGUESA DE RISCOS, PREVENCCÃO E SEGURANÇA

MULTIDIMENSÃO

E
TERRITÓRIOS DE RISCO

III Congresso Internacional

I Simpósio Ibero-Americano

VIII Encontro Nacional de Riscos

Guimarães

2014 


\title{
MAPEAMENTO GEOMORFOLÓGICO DA ÁREA URBANA DE ILHÉUS, BAHIA
}

\author{
Hogana Sibilla Soares Póvoas \\ Bolsista do PET Solos \\ Universidade Estadual de Santa Cruz \\ hogana_sibila@hotmail.com \\ Ednice de Oliveira Fontes \\ Universidade Estadual de Santa Cruz. \\ ednice@uesc.br \\ Ana Maria dos Santos Moreau \\ Universidade Estadual de Santa Cruz \\ amoreau@uesc.br
}

\begin{abstract}
RESUMO
Os estudos geomorfológicos dão importante subsídio para a compreensão da dinâmica da paisagem e contribuem no entendimento da forma de apropriação do espaço pela sociedade. Pois, devido à grande densidade populacional, essas áreas são fortemente alteradas e necessitam de um planejamento adequado para que possam recuperar ou manter o equilíbrio de suas funções (naturais e sociais) visando a mitigação dos riscos geomorfológicos a elas associados Devido à grande densidade populacional, nas áreas urbanas a modificação da natureza é intensa, tornando-se fundamental a análise das características físico-ambientais do território para fins de planejamento. Neste contexto, a presente pesquisa objetivou o mapeamento geomorfológico da cidade de llhéus, na escala de 1:10.000, visando caracterizar as principais formas de relevo, bem como sua origem, processos e riscos. Foram gerados com a utilização do $\operatorname{ArcGis~} 10.0{ }^{\circledR}$, o Modelo Digital de Elevação do Terreno (MDT) contendoas cotas de altitude e o MDT em 3D; o Mapa de Declividade, com as classes propostas por Lepschet al. (1991); o Mapa dos Modelados do Relevo e o mapa de riscos. A elaboração deste mapeamento auxiliará futuras pesquisas científicas, além de subsidiar o planejamento urbano-ambiental na identificação de áreas de risco a enchentes e escorregamentos, identificação e controle de processos erosivos, projetos de conservação e manejo de solo, entre outros.
\end{abstract}

Palavras-chave: Cartografia geomorfológica, Planejamento urbano-ambiental,Sul da Bahia.

\section{Introdução}

A análise geomorfológica é uma importante ferramenta para a compreensão racional da forma de apropriação do espaço pela sociedade, sendo o estudo do relevo uma abordagem essencial no planejamento do território, pois além de caracterizar a morfologia da paisagem, alerta sobre os problemas da influência antrópica.

Nas áreas urbanas, a modificação da natureza pela sociedade se torna intensamente perceptível. Pois, devido à grande densidade populacional, essas áreas são fortemente alteradas e necessitam de um planejamento adequado para que possam recuperar ou manter o equilíbrio de suas funções (naturais e sociais).

A cidade de llhéus possui algumas particularidades, de ordens distintas, mas que se relacionam e apontaram para a necessidade de uma pesquisa geomorfológica na área.Uma é de ordem física, gerada por processos e dinâmicas naturais; outra é como essas características naturais condicionaram sua expansão e; a terceira trata-se dos crescentes problemas socioambientais que a cidade enfrenta.

Ithéus possui uma paisagem com características peculiares no que se refere à compartimentação do relevo. De forma geral, o município apresenta em seu recorte territorial o Domínio Morfoclimático dos Mares de Morros (AB’SÁBER, 1969), Planalto Pré-Litorâneo, Planalto 
Costeiro, Tabuleiros Costeiros e Planície Costeira. Na área urbana, o relevo de Ilhéus apresenta como feições morros, colinas, outeiros e fundos de vale.

A cidade tem um antigo histórico de ocupação e retrata o tipo de urbanização sem planejamento adequado. Apesar da grande importância no contexto histórico da região, a quantidade de estudos detalhados na área, em escala de detalhe compatível, no tocante aos seus atributos físicos ainda é insuficiente. Isso contribui para a dificuldade em propor formas de ocupação apropriadas à cidade.

Como ferramenta para a análise do modelado terrestre destacam-se os mapas geomorfológicos que são importantes instrumentos na análise do relevo,de modo a auxiliar na verificação da forma com que a urbanização se relaciona com a morfologia da paisagem e, a depender da escala, eles mostram claramente como o espaço urbano está assentado sobre os diferentes compartimentos e feições geomorfológicas.

Tendo em vista a ausência de pesquisas com ênfase na geomorfologia da cidade de Ithéus em escala de detalhe compatível (1:10.000) e reconhecendo a importância desses estudos para a análise ambiental e urbana, a presente pesquisa propõe o mapeamento geomorfológico da área urbana de Ilhéus, BA. Após ser concluída, a pesquisa poderá servir de base tanto para trabalhos acadêmicos como para fins de administração pública, facilitando uma proposta de planejamento urbano/ambiental para a cidade.

\section{Metodologia}

O referencial teórico básico para a pesquisa foram os trabalhos de BRASIL (1981), IBGE (1995), Ross (1996), Andrade (2003), Casseti (2005), Araujo (2012), além de artigos e trabalhos científicos publicados em revistas e eventos.

Para a confecção dos mapas e modelos digitais foi utilizado o software ArcGIS 10.0®. O primeiro procedimento metodológico consistiu na delimitação da área urbana de Ilhéus, através do aplicativo ArcMap, do referido software.0 mapa de localização foi gerado a partir de dados disponibilizados no ano de 2010 pela prefeitura municipal de Ithéus e pela Superintendência de Estudos Econômicos e Sociais da Bahia (SEI Bahia).

Posteriormente foi elaborado o Modelo Digital de Elevação do Terreno (MDT) no ArcMap, com base nas curvas de nível igualmente disponibilizadas pela prefeitura de Ithéus.E o MDT em 3 dimensões (3D)com o aplicativo ArcScene, para visualização das feições, no sentido de aprimorar a interpretação para a classificação das diferentes formas do modelado.

Em seguida, no ArcMap foi gerado o mapa de declividade, seguindo a metodologia proposta no Manual para Levantamento Utilitário do Meio Físico e Classificação de Terras no Sistema de Capacidade de Uso, de Lepsch et al.(1991), cujas classes estão expostas no Quadro I. 
Quadro I - Classes de declividade segundo o Manual para Levantamento Utilitário do Meio Físico e Classificação de Terras no Sistema de Capacidade de Uso (LEPSCH et al., 1991).

\begin{tabular}{|c|c|}
\hline Classes de declividade & Limites \\
\hline A & $>2 \%$ \\
\hline B & $2-5 \%$ \\
\hline C & $5-10 \%$ \\
\hline D & $10-15 \%$ \\
\hline E & $15-45 \%$ \\
\hline F & $45-70 \%$ \\
\hline G & $<70 \%$ \\
\hline
\end{tabular}

O mapa dos Modelados do Relevo foi gerado através do ArcMap, tendo por base o MDT. Após a elaboração do Modelo foi utilizada a metodologia do Manual Técnico de Geomorfologia (IBGE, 1995) para a classificação e caracterização dos Domínios, Regiões, Unidades Geomorfológicas e Modelados. Esta classificação possibilita um bom entendimento do mapa das formas tanto para especialistas na área - pesquisadores, planejadores - como para a comunidade, em geral.

A escala de análise utilizada é de 1:10.000 a fim de obter-se um mapa com escala de detalhe compatível à área de estudo, para fins de pesquisa e planejamento. A confecção dos mapas irá auxiliar em uma análise sistemática da paisagem e dar subsídios para o planejamento e gestão da cidade de Ithéus, no que diz respeito às áreas afins dos processos contemplados nesse mapeamento.

\section{Resultados e Discussão}

A partir do levantamento bibliográfico e das curvas de nível disponibilizadas pela prefeitura municipal de llhéus, foi possível utilizar o método mais viável para servir de base ao Mapeamento Geomorfológico da cidade, o Modelo Digital de Elevação do Terreno (MDT).

Reproduzir graficamente a sensação do relevo terrestre, representado espacialmente é um processo prático e acessível, devido aos recursos computacionais atualmente disponíveis, além disso, o desenho panorâmico busca representar as formas tais quais se apresentam (ASPIAZÚ; ALVES; VALENTE, 1990).

As curvas de nível da área urbana de llhéus, com 1:1 m de eqüidistância possibilitaram a elaboração de um MDT com riqueza de detalhes, facilitando a visualização das formas do relevo, além dos valores de altitude (Figura 01). As cotas altimétricas variam de $1 \mathrm{~m}$ nas áreas mais baixas, até $106 \mathrm{~m}$ nos pontos mais altos.

Nas áreas com altitude de até $42 \mathrm{~m}$, concentradas na parte central e a Leste da cidade, localizam-se os Depósitos do Quaternário. De acordo com Brasil (1981), o material encontrado neste local corresponde a sedimentos não consolidados ou pouco consolidados, tendo profundidade de alguns metros até mais de uma centena de metros, sendo essa a faixa mais representativa em relação à área/superfície. Há predomínio de topografia plana, com baixa energia. São encontradas formas meândricas, geradas pela dinâmica fluvial, apresentando planícies de inundação e manguezais nas margens dos rios e próximos ao oceano. 


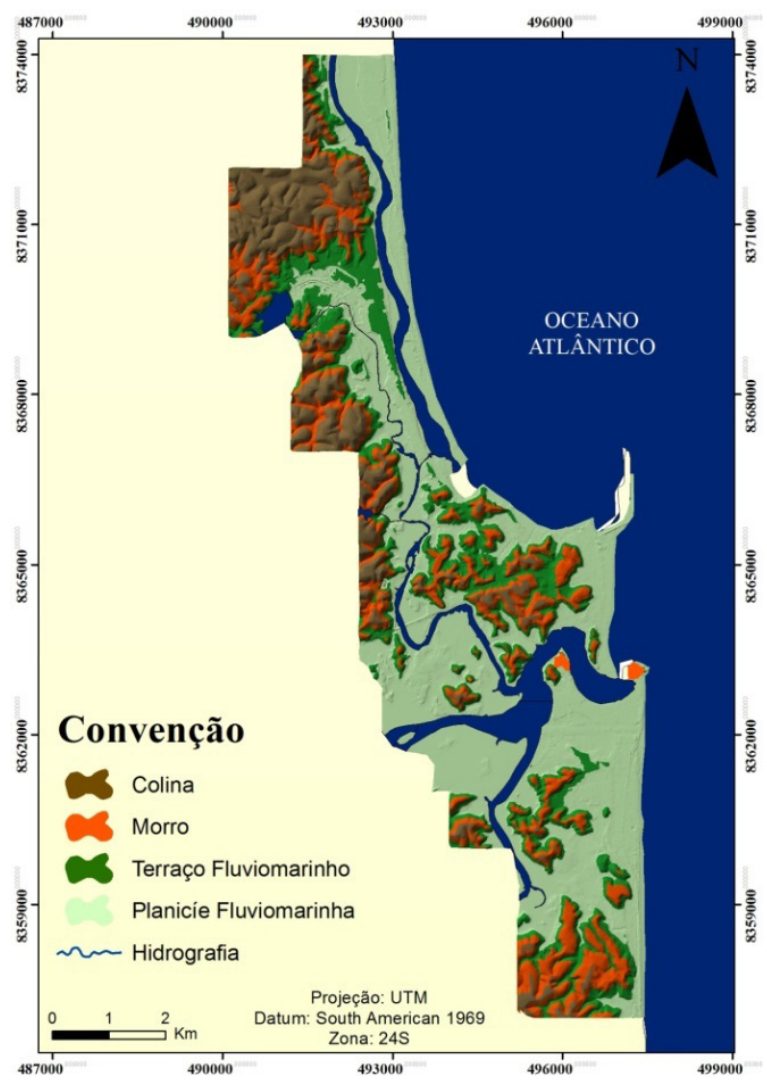

Figura 1 - Mapa de relevo da área urbana de Ilhéus -Ba 2013 Fonte: Elaborado pelo autor, 2013.

Entre as altitudes de 42 a 106 m, situadas na parte central, a Norte e a Oeste, está localizado o Planalto Costeiro. As rochas encontradas nessas áreas são de origem muito antiga, com alto grau de metamorfismo - datam dos ciclos orogenéticos Guriense e Transamazônico (BRASIL, 1981). O relevo apresenta-se plano e suavemente ondulado cortado por vales de baixa energia. Na Figura 2, é apresentado o MDT em 3 dimensões (3D), com enfoque no Centro e Zona Norte de Ithéus. 0 modelo em 3D permite a análise visual através da identificação de modo claro das formas côncavo-convexas e angulosas dos morros e as côncavas dos vales, além do relevo plano da faixa costeira.

Estas áreas da cidade concentram maior densidade de Colinas e Morros em relação às outras Zonas (Sul e Oeste). A altitude mais elevada de toda a cidade é encontrada na Zona Norte, área correspondente à Bacia Hidrográfica do Almada. No Centro, o relevo se apresenta bastante movimentado, com a maior amplitude altimétrica dentre as outras zonas da cidade. 0 modelo em 3D, proporciona a compreensão dos fenômenos espaciais por representar de forma semelhante à realidade a sensação das formas do relevo. 


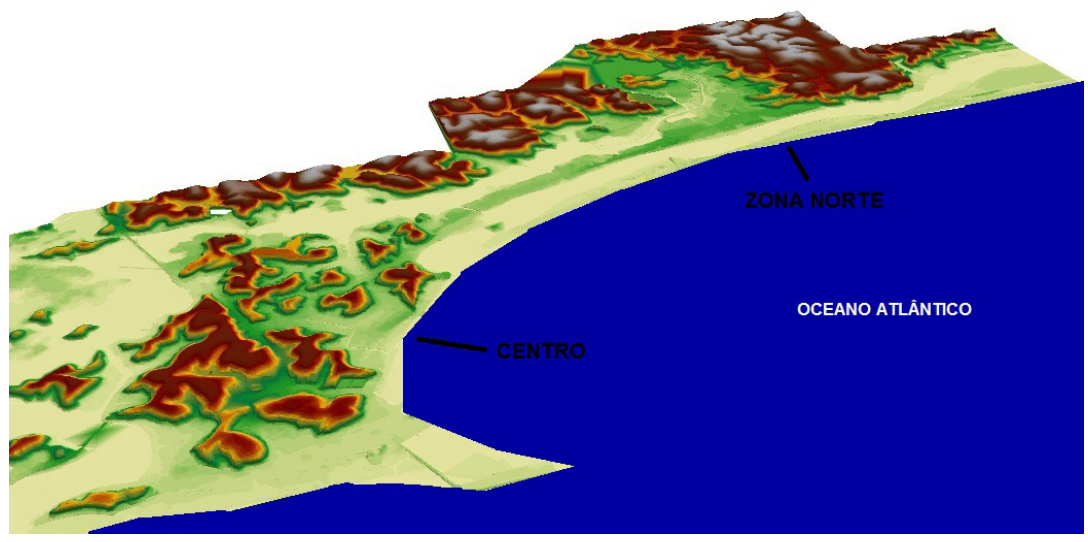

Figura 2 - MDT em 3 Dimensões. Centro e Zona Norte de Ilhéus Fonte: Elaborado pelo autor, 2013.

\section{Conclusões}

Destaca-se a importância da elaboração do presente mapeamento geomorfológico para a cidade de Ilhéus, por ser um documento inédito na escala de 1:10.000. Outro aspecto refere-se à utilização do mapa, para realização de projetos na área de planejamento urbano/ambiental. Devido a sua escala de detalhe, é possível identificar formas de relevo que não eram representadas em escalas menores, bem como seus aspectos (altitude e declividade). Desta forma, o presente trabalho pode fornecer a comunidade acadêmica, bem como a administração pública da cidade um importante embasamento para a compreensão da geomorfologia local.

\section{Referências}

AB `SÁBER, A.N. Um Conceito de Geomorfologia a Serviço das Pesquisas sobre oQuaternário. São Paulo, Geomorfologia, n. 18, p.1-23, 1969.

ANDRADE, M. P. Ilhéus: passado e presente. 2. ed. Ilhéus, Bahia. Editus: 2003.

ARAUJO, I. C. B. Zoneamento Ambiental do município de Ilhéus - BA: uma análise sistêmica. 2012. n. 167, 99 f. Dissertação (Mestrado em Geografia) - Instituto de Geociências, Universidade Estadual de Campinas, Campinas, 2012.

ASPIAZÚ, C; ALVES, L.M; VALENTE, O.F. Modelos digitais de terrenos:conceituação e importância.Boletim de Pesquisa Florestal, Colombo, n. 21, p.27-36, dez. 1990.

BRASIL. Ministério das Minas e Energia. Secretaria Geral. Projeto RADAMBRASIL Folha SD. 24 Salvador: geologia, geomorfologia, pedologia, vegetação e uso potencial da terra. Rio de Janeiro: MME/SG/ Projeto RADAM BRASIL, 1981. (Levantamento de Recursos Naturais, 24).

CASSETI, V. Geomorfologia.2005. Disponível em <http://www.funape.org.br/geomorfologia/>. Acesso em: 03 out. 2012.

IBGE. Manual técnico de Geomorfologia. Manuais Técnicos em Geociências. Rio de Janeiro: IBGE, 1995. nº 5. LEPSCH, I. F. et al.Manual para levantamento utilitário do meio físico e classificação de terras no sistema de capacidade de uso.4 ed. Campinas, São Paulo. Sociedade Brasileira de Ciência do Solo: 1991.

ROSS, J. L. S. Geomorfologia: ambiente e planejamento. 3. ed. São Paulo: Contexto, 1996. 